Published in AIAA Journal, Volume 28, Number 7, July 1990, Pages 1270-1276.

\title{
Mixed-Mode Bending Method for Delamination Testing
}

\author{
James R. Reeder* and John R. Crews Jr.** \\ NASA Langley Research Center, Hampton, Virginia 23665
}

\begin{abstract}
A mixed-mode delamination test procedure was developed combining double cantilever beam (DCB) mode I loading and end-notch fixture (ENF) mode II loading on a split unidirectional laminate. By loading with a lever, a single applied load simultaneously produces mode I and mode II bending loads on the specimen. This mixed-mode bending (MMB) test was analyzed using both finite-element procedures and beam theory to calculate the mode $I$ and mode II components of strain-energy release rate $G_{I}$ and $G_{I I}$, respectively. A wide range of $G_{I} / G_{I I}$ ratios can be produced by varying the load position on the lever. As the delamination extended, the $\mathrm{G}_{\mathrm{I}} / \mathrm{G}_{\mathrm{II}}$ ratios varied by less than $5 \%$. Beam theory equations agreed closely with the finite-element results and provide a basis for selection of $G_{I} / G_{I I}$ test ratios and a basis for computing the mode I and mode II components of measured delamination toughness. The MMB test was demonstrated using AS4/PEEK (APC2) unidirectional laminates. The MMB test introduced in this paper is rather simple and is believed to offer several advantages over most current mixed-mode test.
\end{abstract}

\section{Nomenclature}

$a \quad$ delamination length, $\mathrm{m}$

$b \quad=$ specimen width, $\mathrm{m}$

$c \quad=$ position of applied load on lever, $\mathrm{m}$

$E_{11} \quad=$ lamina longitudinal modulus, GPa

$E_{22} \quad=$ lamina transverse modulus, GPa

$\mathrm{G}=$ total mixed-mode strain energy release rate, $\mathrm{J} / \mathrm{m}^{2}$

$\mathrm{G}_{\mathrm{c}}=$ total mixed-mode delamination fracture toughness, $\mathrm{J} / \mathrm{m}^{2}$

$\mathrm{G}_{\mathrm{I}}=$ mode I strain energy release rate, $\mathrm{J} / \mathrm{m}^{2}$

$\mathrm{G}_{\mathrm{II}}=$ mode II strain energy release rate, $\mathrm{J} / \mathrm{m}^{2}$

$\mathrm{G}_{\mathrm{Ic}}=$ delamination fracture toughness for mode I loading, $\mathrm{J} / \mathrm{m}^{2}$

$\mathrm{G}_{\mathrm{IIc}}=$ delamination fracture toughness for mode II loading, $\mathrm{J} / \mathrm{m}^{2}$

$\mathrm{G}_{\mathrm{Ic}}{ }^{\mathrm{m}}=$ mode I component of $\mathrm{G}_{\mathrm{c}}$ for mixed-mode loading, $\mathrm{J} / \mathrm{m}^{2}$

$\mathrm{G}_{\text {IIc }}{ }^{\mathrm{m}}=$ mode II component of $\mathrm{G}_{\mathrm{c}}$ for mixed-mode loading, $\mathrm{J} / \mathrm{m}^{2}$

$\mathrm{G}_{12}=$ lamina longitudinal shear modulus, $\mathrm{GPa}$

$\mathrm{G}_{13}=$ lamina transverse shear modulus, GPa

$h=$ specimen half-thickness, $\mathrm{m}$

$k=$ stiffness of elastic foundation, $\mathrm{N} / \mathrm{m}^{2}$

$L \quad=$ specimen half-span, $\mathrm{m}$

$P \quad=$ applied load, $\mathrm{N}$

$\mathrm{P}_{\mathrm{I}} \quad=$ mode I load, $\mathrm{N}$

$\mathrm{P}_{\mathrm{II}} \quad$ = mode II bending load, $\mathrm{N}$

$\delta \quad=$ load-point displacement, $\mathrm{m}$

$\lambda=$ elastic foundation parameter, $1 / \mathrm{m}$

*Research Engineer. Materials Division, Mechanics of Materials Branch. **Senior Scientist. Materials Division, Mechanics of Materials Branch.

Introduction

Failures in composite structures often develop as delaminations between plies. Typically, such delaminations initiate and propagate under the combined influence of normal and shear stresses. Therefore, tests of delamination resistance should account for the effects of combined stresses. The present study addresses delamination testing with combined tensile normal stress (mode I) and sliding shear stress (mode II). Various approaches have been used to develop test specimens with such combined normal and shear stresses on the delamination plane. Unfortunately, however, several different types of specimens are often needed to generate delamination toughness data over a desired range of mixed-mode combinations. For example, Fig. 1 shows interlaminar fracture toughness curves measured using three different specimen types.' The pure mode I values for delamination fracture toughness $\mathrm{G}_{\mathrm{Ic}}$ were obtained using a split unidirectional laminate loaded as a double cantilever beam (DCB). The pure mode II values $\mathrm{G}_{\text {IIc }}$ were found using the same type of specimen but subjected to three point bending; this type of test is called an end-notch flexure (ENF) test. ${ }^{2,3}$. However, the mode I and mode II components of mixedmode fracture toughness $\left(\mathrm{G}_{\mathrm{Ic}}{ }^{\mathrm{m}}\right.$ and $\mathrm{G}_{\mathrm{IIc}}{ }^{\mathrm{m}}$, respectively) were generated using cracked-lap shear (CLS) and edge-delamination tension (EDT) specimens. ${ }^{4}$ The use of different test configurations can involve different test variables and analysis procedures that can influence test results in ways that are difficult to predict. The purpose of this paper is to introduce a new test apparatus that can be used to measure delamination toughness over a wide range of mode I/II ratios as well as pure mode I and mode II.

First; the current methods for mixed-mode delamination testing will be briefly reviewed. Next, the proposed mixed-mode

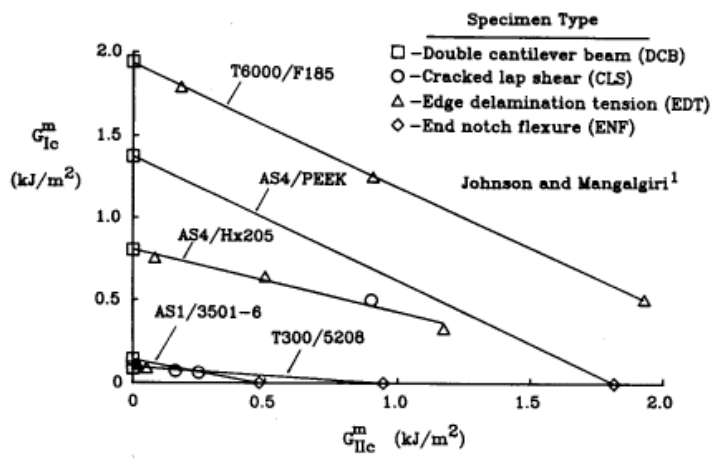

Fig. 1 Delamination toughness for mixed mode I and mode I loading. 
bending (MMB) test is described. Then the total strain energy release rate $\mathrm{G}$ and its mode $\mathrm{I}\left(\mathrm{G}_{\mathrm{I}}\right)$ and mode $\mathrm{II}\left(\mathrm{G}_{\mathrm{II}}\right)$ components will be evaluated for the MMB test specimen using a finite-element analysis. In addition, closed-form equations for $\mathrm{G}_{\mathrm{I}}$ and $\mathrm{G}_{\mathrm{II}}$ will be developed using simple beam theory with modifications to improve their accuracy. Finally, the MMB test method is demonstrated by testing graphite/PEEK (APC2) specimens over a wide range of $\mathrm{G}_{\mathrm{I}} / \mathrm{G}_{\mathrm{II}}$ ratios. Delamination toughness data are presented in terms of the mode I and mode II components of delamination fracture toughness.

\section{Current Mixed-Mode Delamination Tests}

This section briefly reviews current approaches for mixedmode delamination testing. This review provides background for the new approach presented in the next section. Combined mode I and mode II delamination fracture toughness tests usually employ a specimen containing an artificially introduced delamination. The specimen is loaded until the delamination grows. Measured load and delamination length can then be substituted into strain energy release rate equations to calculate the delamination toughness.

A sketch of the CLS specimen is shown in part a of Fig. 2. Uniaxial loading is applied to one arm of a split unidirectional laminate. The load transfer to the other arm causes interlaminar normal stresses (mode I) and interlaminar shear stresses (mode II). Although the CLS specimen can be tested in conventional tension test machines, it has several serious limitations. First, the mode I/II ratios cannot be calculated by simple closed form stress analyses, and, therefore, a numerical analysis is required. Further, because large rotations can result from the load eccentricity at the delamination front, a geometrically nonlinear numerical analysis may be required to evaluate $\mathrm{G}_{\mathrm{I}}$ and $\mathrm{G}_{\mathrm{II}}{ }^{5}$ Also, different ply layups are required to create different mode I/II combinations, and only a rather narrow range of ratios is attainable.

The EDT specimen, shown in part b of Fig. 2 was developed by O'Brien. ${ }^{4}$ A Specimen with a layup such as $(+-35 / 0 / 90)_{\mathrm{s}}$ is loaded in tension, and the mismatch in the Poisson's ratios of the plies causes high edge stresses at the $0 / 90$ ply interfaces. The loadinduced mode I and mode II stresses at these interfaces can initiate edge delaminations. Unfortunately, however, hygrothermal interlaminar stresses also exist at this interface and can seriously reduce the measured delamination toughness. ${ }^{6}$ Also, numerical analyses are required to calculate the interlaminar $\mathrm{G}_{\mathrm{I}}$ and $\mathrm{G}_{\mathrm{II}}$ components in the EDT test.

In the Arcan test configuration, part $\mathrm{c}$ of Fig. 2, a split unidirectional laminate is bonded between two metal fixtures that
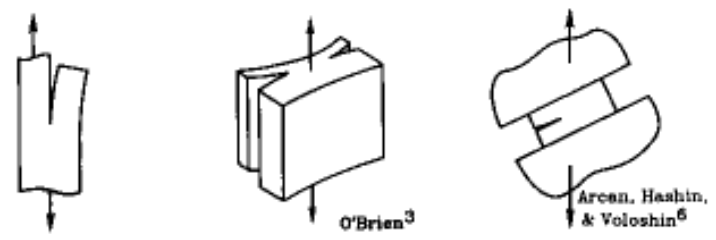

(a) Cracked lap shear

(b) Edge delamination tension.

(c) Arcan

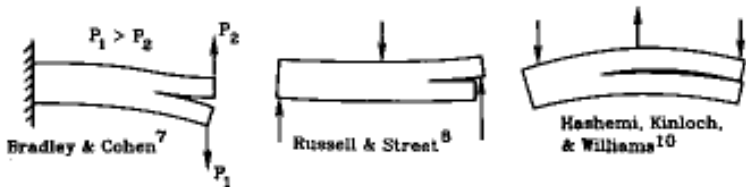

(d) Asymmetric DCB (e) Mixed-mode flexure. (f) Variable mixed-mode. Fig. 2 Mixed mode 1 and mode II delamination test specimens. can be loaded to produce various mixed-mode conditions at the delamination front. ${ }^{7}$ But, as with the CLS and EDT tests, the mode I/II ratio must be determined by a numerical analysis. Also, bond failures can limit the Arcan test use, especially for tough laminates.

The asymmetric DCB test, proposed by Bradley and Cohen, ${ }^{8}$ avoids most of the problems found with the first three methods. As shown in part d of Fig. 2, this approach involves loading the arms of a unidirectional DCB specimen with two different loads. The loads can be selected to produce the full range of mode I/II ratios. Equal and opposite loads produce a pure mode I delamination, and equal loads produce a pure mode II delamination. Unfortunately, the asymmetric DCB approach requires a complex loading system to control the two applied loads simultaneously.

The mixed-mode flexture test, proposed by Russell and Street, ${ }^{9}$ is shown in part e of Fig. 2. This test specimen is similar to the CLS specimen but is loaded in three-point bending. Unfortunately, different arm thicknesses are required to produce different mode I/II ratios. This requires that specimens be fabricated with the delamination starter at different ply interfaces. Also different arm thicknesses can influence the stress distribution ahead of the delamination ${ }^{10}$ and, therefore, may influence toughness measurements.

The variable mixed-mode test in part $\mathrm{f}$ of Fig. 2 was proposed by Hashemi et al. ${ }^{11}$ A pure mode II condition is created when the delamination tip is centered under the midspan tension load. The mode I/II ratio increases as the delamination extends toward the left load point. A pure mode I condition exists when the delamination is under the left load point. As a result, the full range of mode I/II ratios can be produced. However, the ratio changes as the delamination grows. This could complicate the data analysis-especially for large increments of unstable growth. Also, when the delamination tip is near either load point, simple closed form equations for $\mathrm{G}_{\mathrm{I}}$ and $\mathrm{G}_{\mathrm{II}}$ will not account for the complex effects of load concentrations or loading fixture stiffness.

\section{Mixed-Mode Bending Test}

The MMB test simply combines the mode I DCB and the mode II ENF tests. This is achieved by adding an openingmode load to a mid-span loaded ENF specimen as shown in part a of Fig. 3. This additional load separates the arms of the split unidirectional laminate as in a DCB test. The relative magnitudes of the two applied loads determines the mixed-mode ratio at the delamination front. By applying these two loads through a lever and hinge apparatus as shown in part b of Fig. 3, the test can be conducted by applying a single load. The loading position $c$

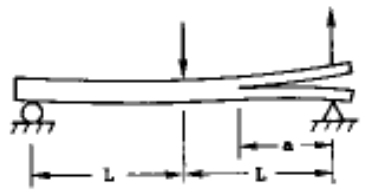

(a) Test specimen and loading.

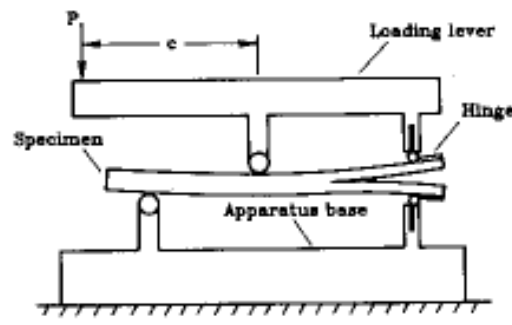

(b) Schematic diagram of apparatus

Fig. 3 Mixed-mode bending specimen and test apparatus. 

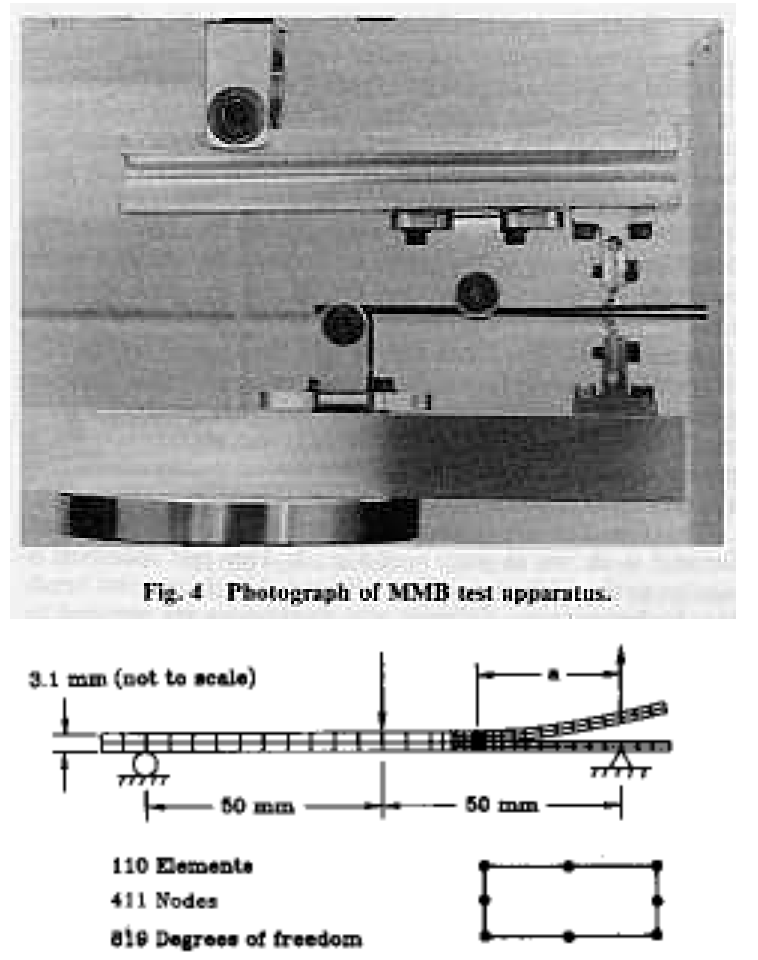

o Noded quadrilateral element

Fig. 5 Finite-element model for MMB specimen.

determines the relative magnitude of the two resulting loads on the specimen and, therefore, determines the mixed-mode delamination ratio. Pure mode II loading occurs when the applied load is directly above the beam midspan $(c=0)$. Pure mode I loading can be achieved by removing the beam and pulling up on the hinge.

A photograph of the MMB test apparatus is shown in Fig. 4. The loading lever is an aluminum I-beam weighing only $6 \mathrm{~N}$, which was assumed to be a negligible weight. The lever is several orders of magnitude stiffer than the specimen and, therefore, was assumed to be rigid. The lever load, the midspan load, and the left support reaction are applied through bearing-mounted rollers to reduce frictional forces. The right end of the specimen is loaded through high-quality, extruded aluminum hinges bonded to the specimen arms. The specimen in this photograph is a 24-ply graphite/PEEK unidirectional laminate, 102-mm long, 25-mm wide, and 3.1-mm thick. The apparatus is mounted on a thick steel base.

\section{Stress Analysis}

This section presents the stress analysis of the MMB test specimen and focuses on the calculation of strain energy release rates. The $\mathrm{G}_{\mathrm{I}} / \mathrm{G}_{\mathrm{II}}$ ratio is needed to resolve the measured mixedmode delamination fracture toughness $\mathrm{G}_{\mathrm{c}}$ into its mode I and II components, $\mathrm{G}_{\mathrm{Ic}}{ }^{\mathrm{m}}$ and $\mathrm{G}_{\mathrm{IIc}}{ }^{\mathrm{m}}$, respectively. First, a finite-element analysis was used to provide a basic understanding of the strainenergy release rate during MMB testing. Next, a more convenient beam-theory analysis is presented, and its results are compared with those from the finite-element analysis. Finally, the simple beam theory analysis was modified to improve its accuracy.

\section{Finite-Element Analysis}

The MMB specimen was modeled and loaded as shown in Fig. 5. Eight-noded quadrilateral elements were used with the MSC NASTRAN finite-element code. ${ }^{12}$ To account for the effect of an uneven fiber distribution through the specimen thickness, an effective modulus was calculated from a three-point bend test. ${ }^{13}$ Measured midspan displacements and loads were used with beam

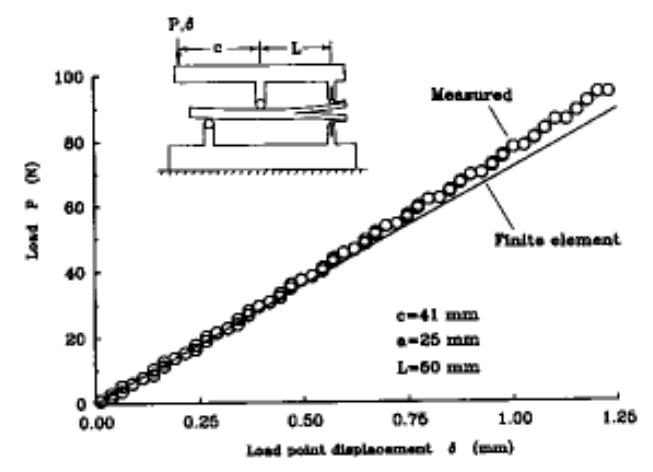

Fig. 6 Comparison of computed and measured load-displacement curves.

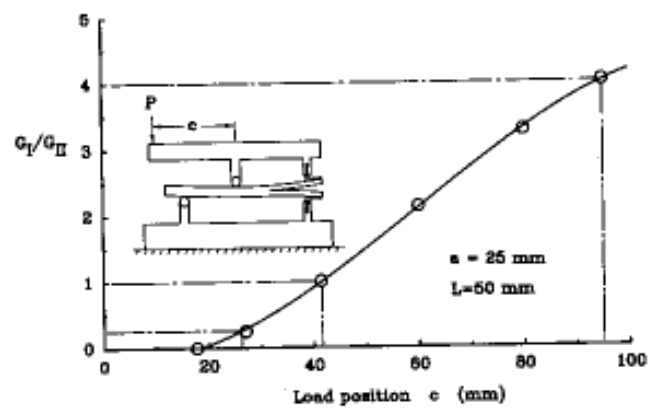

Fig. 7 Load position for mixed-mode testing.

theory to calculate the longitudinal modulus $E_{11}$ for the laminate. An effective $E_{11}$ of $116 \mathrm{GPa}$ was determined by this approach, compared to the uniaxial tension value of $129 \mathrm{GPa}$ from Ref. 14. A transverse modulus $E_{22}$ of $10.1 \mathrm{GPa}$, a Poisson's ratio $v_{12}$ of 0.329 , and shear modulus $\mathrm{G}_{12}$ of $5.5 \mathrm{GPa}$ were used. ${ }^{14}$

The finite-element modeling was evaluated by comparing the computed load-displacement results with measured results. The solid line in Fig. 6 represents the computed finite-element results, and the symbols show measurements taken during loading and unloading of the MMB apparatus. The load-point displacement was determined from the crosshead position. The solid curve agrees with the test data very well in the lower load range and slightly overestimates the displacements in the upper range. The discrepancy may be caused by geometric nonlinearity, which was not accounted for by the finite-element analysis. However, the correlation in this figure does suggest that the finite-element model is sufficiently accurate to analyze the MMB specimen. Crack-tip forces and displacements were used in the virtual crack closure technique ${ }^{15}$ to calculate $\mathrm{G}_{\mathrm{I}}$ and $\mathrm{G}_{\mathrm{II}}$ for the MMB specimen.

As just mentioned, the load position $c$ determines the ratio of mode I and mode II. To establish a relationship between $c$ and the $\mathrm{G}_{\mathrm{I}} / \mathrm{G}_{\mathrm{II}}$ ratios, the finite-element analysis was repeated for several values of $c$. This relationship is shown in Fig. 7, where the symbols are the computed values and the solid line is a best-fit curve. The test data shown previously in Fig. 1 suggest that a mixed-mode toughness curve could be established reasonably well using five test cases: three mixed-mode and the two pure mode toughness tests. In the present study, mixed-mode ratios of $4 / 1,1 / 1$, and $1 / 4$ were selected. As shown in Fig. 7, the three corresponding $c$ values

$$
G_{1}=\frac{12 a^{2} P_{1}^{2}}{b^{2} h^{3} E_{11}}
$$

are 95,41 , and $27 \mathrm{~mm}$, respectively. Although the present study was limited to three mixed-mode ratios, the MMB apparatus can be used to measure any $\mathrm{G}_{\mathrm{I}} / \mathrm{G}_{\mathrm{II}}$ ratio from zero to approximately five. Notice that $\mathrm{G}_{\mathrm{I}} / \mathrm{G}_{\mathrm{II}}$ is zero for $c$ less than about $18 \mathrm{~mm}$. Below 
this value, the mode I loading is not large enough to overcome the crack-face normal stresses produced by the mode II loading. Hence, the delamination does not open, and $\mathrm{G}_{\mathrm{I}}$ must be zero within this range despite the nonzero $c$ values. As just mentioned, the mode II tests were conducted with $c$ equal to zero.

Finite element analyses of the MMB specimen were conducted to determine the variation of the strain energy release rate during delamination. A half-span length of $50 \mathrm{~mm}$ was used, and analyses were conducted for delamination lengths from about 20 to $45 \mathrm{~mm}$. Figure 8 shows computed values of total strain energy release rate $\mathrm{G}$ for the pure mode I and mode II cases plotted over a range of delamination lengths. The two curves in this figure represent limits for the mixed-mode cases. For convenience, G values are normalized by the square of the load-point displacement. If the curves are interpreted as $\mathrm{G}$ variations during delamination growth under constant displacement $\delta$, then they can be compared with toughness $\mathrm{G}_{\mathrm{c}}$ to predict if delamination growth is unstable $\left(\mathrm{G}\right.$ continues to equal or exceed $\mathrm{G}_{\mathrm{c}}$ as the delamination grows) or is stable ( $\mathrm{G}$ falls below $\mathrm{G}_{\mathrm{c}}$ ) requiring additional loading for subsequent growth. The negative slope of the mode I curve shows that delamination growth in a DCB test should be stable. In contrast, the peak of the mode II curve at $35 \mathrm{~mm}$ suggests delamination growth would be unstable for delamination lengths less than this value but stable for longer lengths.

The $\mathrm{G} / \delta^{2}$ curves for the three mixed-mode loading cases are shown in Fig. 9. The case where mode $\mathrm{I}$ is dominant $\left(\mathrm{G}_{\mathrm{I}} / \mathrm{G}_{\mathrm{II}}=4 / 1\right)$ has a curve with a negative slope, which indicates stable delamination growth as in the pure mode I case shown in Fig. 8. The $1 / 1$ and the $1 / 4$ curve both indicate a region of unstable growth below delamination lengths of 25 and $30 \mathrm{~mm}$, respectively. As expected, a higher mode II component in the mixed-mode test results in a larger region of instability.

Ratios of $\mathrm{G}_{\mathrm{I}} / \mathrm{G}_{\mathrm{II}}$ are plotted vs delamination length in Fig. 10. Preferably, this ratio should be constant throughout the test range

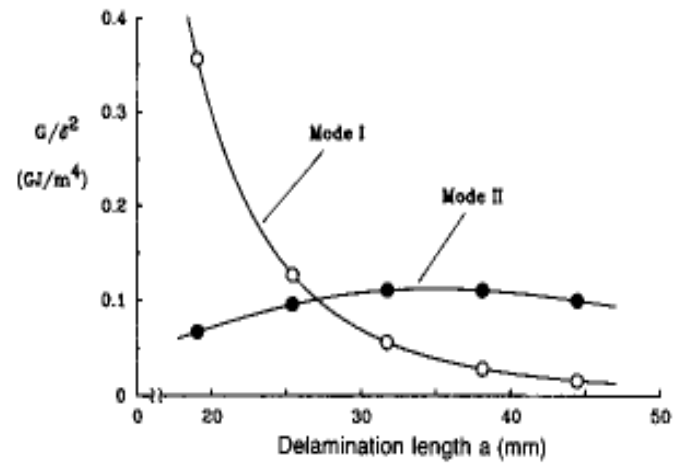

Fig. 8 Stain energy release rates for pure mode I and mode II loading.

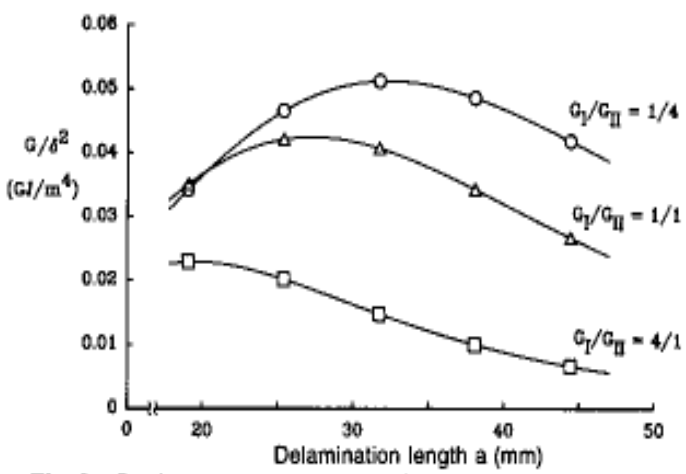

Fig. 9 Strain energy release rates for mixed-mode loading. of delamination lengths. The horizontal lines in Fig. 10 represent the $4 / 1,1 / 1$, and 114 mixed-mode ratios and pass through the computed values for the $25 \mathrm{~mm}$ delamination length. (Recall that a $25 \mathrm{~mm}$ delamination length was used in Fig. 7 to establish the load position $c$ for each of the three mixed-mode cases.) Within the useful test range (delamination lengths from 25 to $45 \mathrm{~mm}$ ), the $\mathrm{G}_{\mathrm{I}} / \mathrm{G}_{\mathrm{II}}$ ratios deviated from the nominal values by only about $5 \%$. This small deviation shows that the $\mathrm{G}_{\mathrm{I}} / \mathrm{G}_{\text {II }}$ ratio can be assumed to be constant during delamination growth for the MMB test.

Beam-Theory Analysis

Although the finite-element analysis provided an accurate strain energy release rate analysis of the MMB specimen, a closed-form analysis offers many advantages in setting up MMH specimen tests and evaluating test results. A closed-form analysis also shows the functional relationships among the test parameters, which improves the basic understanding of the MMB test. This section presents strain energy release rate equations based on beam theory. The MMB loading was represented by a superposition of simple mode I and mode II loadings, equivalent to those used with DCB and ENF tests, respectively. Thus, strain energy release rate equations from the literature on DCB and ENF tests could be combined to obtain the desired equations for the MMB test.

Part a of Fig. 11 shows the MMB loading expressed in terms of the applied load $P$, the loading lever length $c$, and the specimen half-span $L$. As shown in part $\mathrm{b}$ of Fig. 11, the mode I component of this loading is

$$
P_{1}=\left(\frac{3 c-L}{4 L}\right) P
$$

Simple beam theory analysis of the DCB specimen leads to

$$
G_{1}=\frac{12 a^{2} P_{1}^{2}}{b^{2} h^{3} E_{11}}
$$

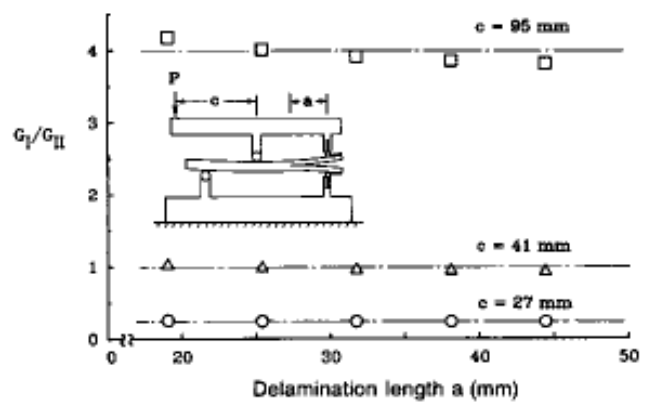

Fig. $10 G_{1} / G_{11}$ ratio for mixed-mode loading.
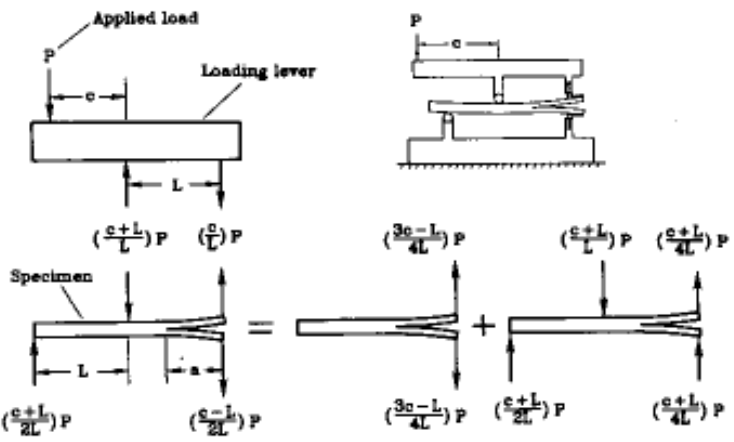

(a) MMB specimen loading. (b) Mode I loading. (c) Mode II loading. Fig. 11 Superposition anlysis of loading on the MMB specimen. 


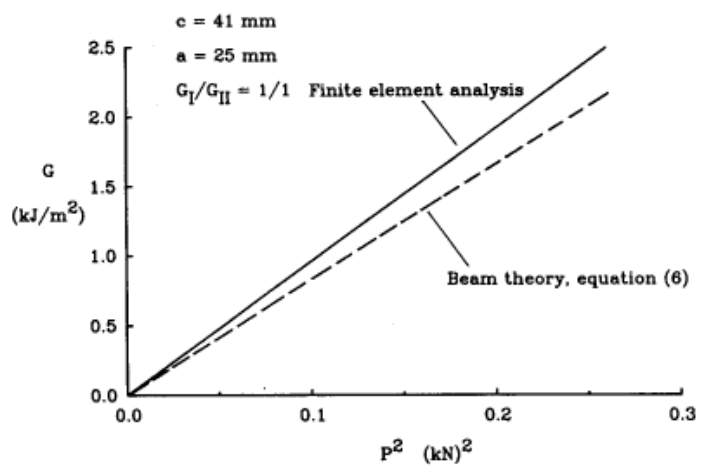

Fig. 12 Comparison of beam-theory and finite-element results.

Substituting for $P_{I}$ leads to the following equation for $G_{I}$, of the MMB test

$$
G_{1}=\frac{3 a^{2} P^{2}}{4 b^{2} h^{3} L^{2} E_{11}}(3 c-L)^{2}
$$

Part $\mathrm{c}$ of Fig. 11 shows the mode II portion of the MMB loading. Note that the right-end loading has been divided equally between the two equal-stiffness arms of the specimen. This is equivalent to the conventional loading of the ENF test. For the ENF test, the mode II bending load is

$$
P_{\mathrm{II}}=\left(\frac{c+L}{L}\right) P
$$

as shown in part $\mathrm{c}$ of Fig. 11. The following equation for $\mathrm{G}_{\mathrm{II}}$ of the ENF test was presented in Ref. 3.

$$
G_{\mathrm{II}}=\frac{9 a^{2} P_{\mathrm{II}}^{2}}{16 b^{2} h^{3} E_{11}}
$$

Substituting for $\mathrm{P}_{\mathrm{II}}$, the corresponding equation for $\mathrm{G}_{\mathrm{II}}$ of the MMB test is

$$
G_{11}=\frac{9 a^{2} P^{2}}{16 b^{2} h^{3} L^{2} E_{11}}(c+L)^{2}
$$

By dividing Eq. (2) by Eq. (4), the $\mathrm{G}_{\mathrm{I}} / \mathrm{G}_{\mathrm{II}}$ ratio for the MMB test can be expressed as

$$
G_{\mathrm{I}} / G_{\mathrm{II}}=\frac{4}{3}\left[\frac{(3 c-L)}{(c+L)}\right]^{2} \quad c \geq \frac{L}{3}
$$

Notice that $\mathrm{G}_{\mathrm{I}} / \mathrm{G}_{\mathrm{II}}$ is only a function of load position $c$ and halfspan length $L$. The $\mathrm{G}_{\mathrm{I}} / \mathrm{G}_{\text {II }}$ ratio is zero for $c=L / 3(c=17 \mathrm{~mm}$ for the present study), and Eq. (5) is invalid for smaller $c$ values because this model does not account for contact between the two arms of the specimen. The total strain energy release rate for the MMB test is obtained by adding Eqs. (2) and (4).

$$
G=\frac{3 a^{2} P^{2}}{16 b^{2} h^{3} L^{2} E_{11}}\left[4(3 c-L)^{2}+3(c+L)^{2}\right]
$$

Equation (6) is compared with the finite element results in Fig. 12. These results for a $25-\mathrm{mm}$ delamination with $\mathrm{G}_{\mathrm{I}} / \mathrm{G}_{\mathrm{II}}$ equal to unity show that Eq. (6) underestimates $\mathrm{G}$ by about $15 \%$. To analyze this discrepancy, $\mathrm{G}_{\mathrm{I}}$ and $\mathrm{G}_{\mathrm{II}}$ were calculated using Eqs. (2) and (4) and are compared with the corresponding finite-element results in Fig. 13. The $\mathrm{G}_{\mathrm{I}}$ values are $18 \%$ low and the $\mathrm{G}_{\mathrm{II}}$ values are only $6 \%$ low. This indicates that most of the error in Eq. (6) can be attributed to the $\mathrm{G}_{\mathrm{I}}$ component and, therefore, to the beam theory equation for the DCB test.

Kanninen ${ }^{16}$ introduced an improved beam theory equation for the DCB test. He recognized that simple beam theory did not properly model the interaction between the two arms of the DCB specimen. The two arms are not fixed against rotation at the

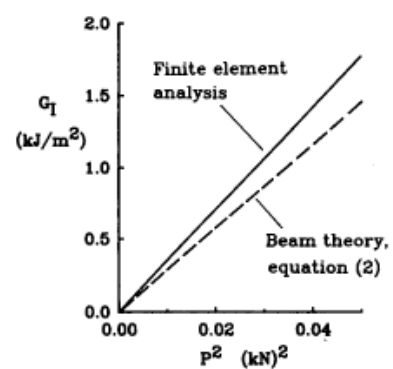

(a) Mode I

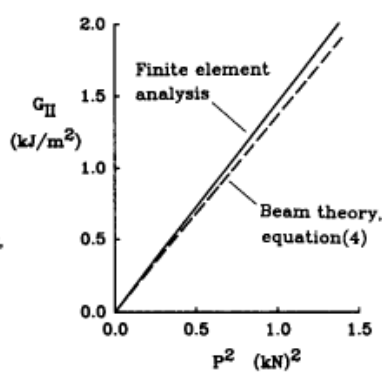

(b) Mode II
Fig. $13 G_{1}$ and $G_{I I}$ components from beam-theory and finite-element analysis.

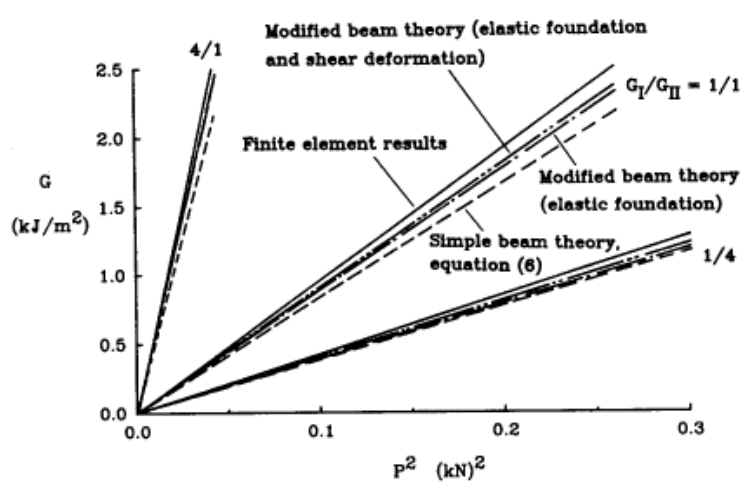

Fig. 14 Comparison of $\boldsymbol{G}$ results for mixed-mode loading cases.

delamination tip as assumed in simple beam theory. Instead, they rotate slightly due to the elastic support that they provide one another. To account for this, Kanninen assumed that each arm was a beam supported by an elastic foundation. His analysis of an isotropic DCB specimen was extended to an orthotropic DCB specimen by replacing $\mathrm{E}$ with $\mathrm{E}_{11}$ and $\mathrm{E}_{22 .}{ }^{17}$

$$
G_{1}=\frac{12 P_{1}^{2}}{b^{2} h^{3} E_{11}}\left[a^{2}+\frac{2 a}{\lambda}+\frac{1}{\lambda^{2}}\right]
$$

where

$$
\lambda=\left(3 k / b h^{3} E_{11}\right)^{1 / 4}
$$

and

$$
k=2 b E_{22} / h
$$

The beam theory equations for strain energy release rate can be further improved by accounting for the shear deformation energy associated with bending. Adding the shear deformation component of strain energy release rate ${ }^{18}$ to Eq. (7) leads to the following modified beam theory equation for $\mathrm{G}_{\mathrm{I}}$ in the MMB test.

Similarly, adding the shear deformation term from Ref. 19 to Eq. (4) results in a modified beam theory equation for $\mathrm{G}_{\text {II }}$ in the MMB test.

$$
G_{\mathrm{I}}=\frac{3 P^{2}(3 c-L)^{2}}{4 b^{2} h^{3} L^{2} E_{11}}\left[a^{2}+\frac{2 a}{\lambda}+\frac{1}{\lambda^{2}}+\frac{h^{2} E_{11}}{10 G_{13}}\right]
$$

Assuming the unidirectional composite specimens used in the present study are transversely isotropic, the shear modulus 613 in these two equations can be replaced by $\mathrm{G}_{12}$.

$$
G_{11}=\frac{9 P^{2}(c+L)^{2}}{16 b^{2} h^{3} L^{2} E_{11}}\left[a^{2}+\frac{0.2 h^{2} E_{11}}{G_{13}}\right]
$$

The total $\mathrm{G}$ values for the MMB test were recalculated using the 
modified beam theory of Eqs. (8) and (9). Figure 14 compares the $\mathrm{G}$ calculations for the three-beam theory equations with the finiteelement results. For the earlier case of $\mathrm{G}_{\mathrm{I}} / \mathrm{G}_{\mathrm{II}}$ equal to unity, $\mathrm{G}$ calculated with the elastic foundation correction (dash-dot curve) agreed with the finite-element values (solid Curve) with an error of about $8 \%$ compared to the $14 \%$ error for the simple beam theory (dashed Curve). The additional modification for shear deformation led to the dash-double dot curve, which is within about $6 \%$ of the finite-element results. The corresponding errors for the $4 / 1$ and $1 / 4$ cases were also only about $6 \%$.

Next, Eqs. (8) and (9) were used to recalculate the $\mathrm{G}_{\mathrm{I}} / \mathrm{G}_{\mathrm{II}}$ ratios for the three mixed-mode test cases. Recall that the values of $c$ for the three $\mathrm{G}_{\mathrm{I}} / \mathrm{G}_{\text {II }}$ ratios of $4 / 1,1 / 1$, and $1 / 4$ were selected earlier using finite-element results for a $25-\mathrm{mm}$ delamination (see Fig. 7). The recalculated $\mathrm{G}_{\mathrm{I}} / \mathrm{G}_{\mathrm{II}}$ ratios are shown as the solid curves in Fig. 15 and are compared with the discrete finite-element values shown by symbols. These curves agree very well with the finite-element values. Within the 25 -to $45-\mathrm{mm}$ range of delamination lengths, the modified beam theory ratios vary by about 3,5 , and $8 \%$ from the finite-element results for the $4 / 1,1 / 1$ and $1 / 4$ cases, respectively.

Compared to the finite-element analysis, the modified beam theory of Eqs. (8) and (9) appear to provide acceptably accurate values of $\mathrm{G}_{\mathrm{I}}$ and $\mathrm{G}_{\mathrm{II}}$ for the MMB test. Before testing, Eqs. (8) and (9) can be used to select the loading positions that produce desired $\mathrm{G}_{\mathrm{I}} / \mathrm{G}_{\mathrm{II}}$ test ratios. After testing, measured values of delamination length and the corresponding MMB specimen loads can be substituted into these equations to calculate the mode I and mode II delamination fracture toughness components $\mathrm{G}_{\mathrm{Ic}}{ }^{\mathrm{m}}$ and $\mathrm{G}_{\mathrm{IIc}}{ }^{\mathrm{m}}$. Because both the finite-element and beam-theory analyses presented here are linear, they do not account for possible effects due to geometric nonlinearities. Such effects should be the subject of future research.
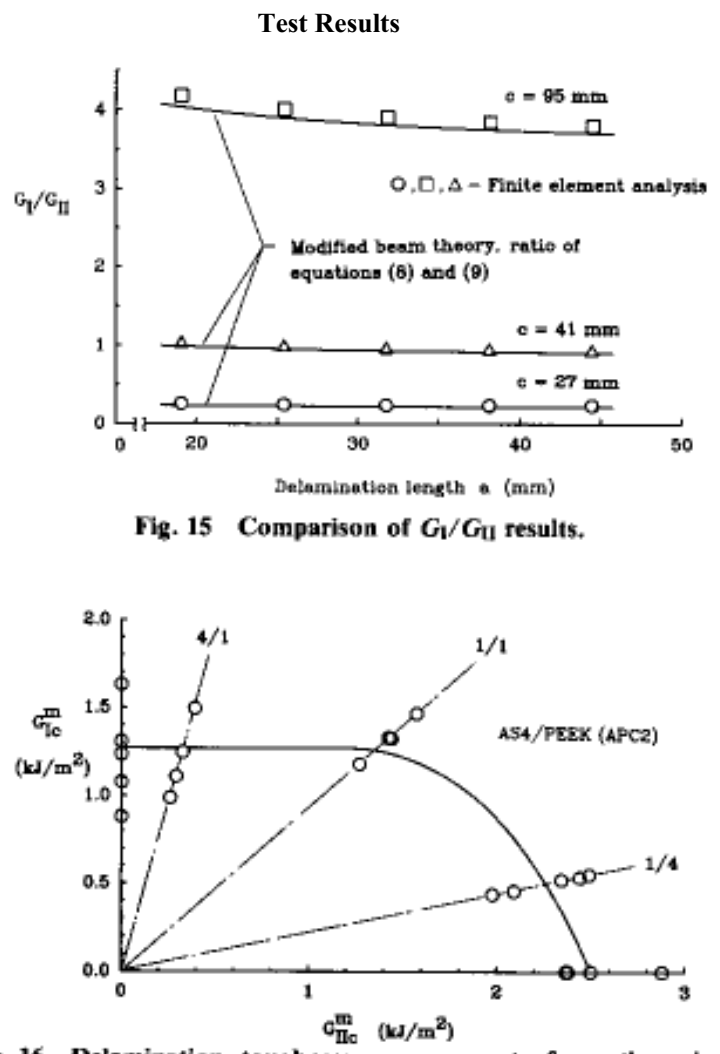

Fig. 16 Delamination toughness measurements from the mixedmode bending test.
As mentioned in the preceding discussion, tests were conducted with 24-ply unidirectional AS4/PEEK (APC2) specimens. These specimens were $25-\mathrm{mm}$ wide and contained a Kapton film delamination starter at one end of the specimen. The Kapton film was $25-\mathrm{mm}$ wide, $25-\mathrm{mm}$ long, $13 \mu \mathrm{m}$ thick, and located at the specimen midplane. To produce an initial delamination, each specimen was precracked to about $30 \mathrm{~mm}$ using the $4 / 1$ mixedmode ratio. No significant fiber bridging was observed at this mixed-mode ratio. The $\mathrm{G}_{\mathrm{I}} / \mathrm{G}_{\mathrm{II}}$ mixed-mode ratios of $4 / 1,1 / 1$, and $1 / 4$ were produced by selecting the load positions from Fig. 7. Pure mode 11 tests were conducted by applying the load at the specimen midspan $(c=0)$. For the pure mode I case, the loading lever was removed, and an upward load was applied directly through the upper hinge on the specimen. Each specimen was loaded under displacement control with a rate of $0.5 \mathrm{~mm} / \mathrm{mm}$ until the delamination grew. The maximum load was recorded, and the delamination length was measured visually at the specimen edges. The edges had been coated with white water soluble typewriter correction fluid to make the delamination easier to see.

The delamination growth was usually stable, and delamination growth increments were about $5 \mathrm{~mm}$. The tests were stopped when the delamination reached $45 \mathrm{~mm}$ in length, and specimens were split apart to examine the markings usually produced by the loading-unloading sequence. These markings provided accurate measurements of delamination length and where used to verify the measurements taken during testing. The recorded values for load and delamination length were used in Eqs. (8) and (9) to calculate $\mathrm{G}_{\mathrm{Ic}}{ }^{\mathrm{m}}$ and $\mathrm{G}_{\mathrm{IIc}}{ }^{\mathrm{m}}$, respectively.

Test results are presented in Fig. 16 with $\mathrm{G}_{\mathrm{Ic}}{ }^{\mathrm{m}}$ plotted against $\mathrm{G}_{\mathrm{IIc}}{ }^{\mathrm{m}}$. Each symbol represents a toughness measurement corresponding to growth from the precrack. The data exhibited considerable scatter, but this is somewhat typical of delamination testing. The solid curve fitted through the data can be viewed as a delamination failure criterion for mixed-mode loading. The curve is nearly horizontal in the region where $\mathrm{G}_{\mathrm{Ic}}{ }^{\mathrm{m}} / \mathrm{G}_{\mathrm{IIc}}{ }^{\mathrm{m}}>1$ indicating that the toughness is nearly independent of $\mathrm{G}_{\mathrm{II}}$, and therefore, delamination growth was controlled by mode I loading. In the region where $\mathrm{G}_{\mathrm{I}} / \mathrm{G}_{\mathrm{II}}<1$, the curve is sloped indication that both mode I and mode II loading influence the delamination toughness.

Fracture toughness was also measured when the precracks were initiated from the Kapton insert using the 4/1 loading condition. The average toughness from the precracking differed by only $2 \%$ from the data shown in Fig. 16 for the 4/1 case. This suggests that precracking may not have been necessary.

\section{Concluding Remarks}

A MMB delamination test procedure has been presented for a split unidirectional laminate. The mixed-mode loading was created by combining the model loading for the DCB test with that for the mode II ENF test. This combined loading was produced using a loading lever, and the ratio of mode I to mode II was varied by changing the load position on the lever. Both finite-element analysis and beam-theory analyses were conducted to determine the mode I and mode II components of strain energy release rate $G_{I}$ and $\mathrm{G}_{\mathrm{II}}$, respectively. The MMB test procedure was demonstrated by measuring the mixed-mode delamination fracture toughness of AS4/PFFK (APC2) unidirectional laminates.

Finite element analyses were conducted to determine the loading lever lengths necessary to produce the desired mixed-mode ratios of $4 / 1,1 /$ land $1 / 4$. The finite-element analysis showed that these ratios varied by less than $5 \%$ over a $20-\mathrm{mm}$ test range of delamination lengths. Therefore, the $\mathrm{G}_{\mathrm{I}} / \mathrm{G}_{\mathrm{II}}$ ratio can be assumed to be independent of delamination length.

Beam-theory equations from the literature for DCB and ENF tests 
were used with a superposition procedure to develop equations for $\mathrm{G}_{\mathrm{I}}$ and $\mathrm{G}_{\mathrm{II}}$ for the MMB test. These equations were then modified using elastic foundation and shear deformation analyses. The resulting modified equations for $\mathrm{G}_{\mathrm{I}}$ and $\mathrm{G}_{\mathrm{II}}$ were within about $6 \%$ of the finite-element results. Measured delamination lengths and loads from the MMB tests were substituted into these equations to determine the mode I and mode II components of delamination toughness during mixed-mode delamination. Pure mode I and mode II tests were also conducted by simplifying the MMB test to produce DCB and ENF loadings, respectively. This approach provided delamination fracture toughness data over a wide range of $\mathrm{G}_{\mathrm{I}} / \mathrm{G}_{\mathrm{II}}$ ratios using identical test specimens and procedures.

The MMB test is a rather simple and direct combination of DCB and ENF tests and seems to offer several advantages over most current mixed-mode delamination tests. Many of the data reduction procedures that have been developed for the $\mathrm{DCB}$ and ENF tests should be applicable to the MMB test because of its similarities with these pure-mode tests. Also, DCB and ENF studies of test parameters such as insert thickness and precracking may be applicable to the MMB test. Therefore, it should be relatively easy to use MMB testing beyond the initial procedures of the present study.

\section{References}

${ }^{1}$ Johnson, W. S., and Mangalgiri, P. D., "Influence of the Resin on Interlaminar Mixed-Mode Fracture," Toughened Composites, edited by Norman J. Johnston, American Society for Testing and Materials, Philadelphia, ASTM STP 937, 1987, pp.295-315.

${ }^{2}$ Barrett, J. D., and Foschi, R. 0., "Mode II Stress Intensity Factors for Cracked Wood Beams," Engineering Fracture Mechanics, Vol.9, No.2, 1977, pp.371-378.

${ }^{3}$ Russell, A. J., "On the Measurement of Mode II Interlaminar Fracture Energies," Defence Research Establishment Pacific, Victoria, Canada, DREP Materials Rept. 82-0, Dec.1982.

${ }^{4} 0$ 'Brien, T. K., "Mixed-Mode Strain-Energy-Release Rate Effects on Edge Delamination of Composites," Effects of Defects in Composite Materials, American Society for Testing and Materials, Philadelphia, ASTM STP 836, 1984, pp.125-142.

${ }^{5}$ Johnson, W. S., "Stress Analysis of the Cracked-Lap-Shear Specimen: An ASTM Round-Robin," Journal of Testing and Evaluation, Vol.15, No.6, Nov.1987, pp.303-324.

${ }^{6} 0$ 'Brien, T. K., Raju, I. S., and Garber, D. P., "Residual Thermal and Moisture Influences on the Strain Energy Release Rate Analysis of Edge Delamination," Journal of Composites Technology \& Research, Vol.8, No.2, Summer 1986, pp.37-47.

${ }^{7}$ Arcan, M., Hashin, Z., and Voloshin, A., "A Method to

Produce Uniform Plane-Stress States with Applications to FiberReinforced Materials," Experimental Mechanics, Vol.8, April 1978, pp.141-146.

${ }^{8}$ Bradley, W. L., and Cohen, R. N., "Matrix Deformation and Fracture in Graphite-Reinforced Epoxies," Delamination and Debonding of Materials, edited by W. S. Johnson, American Society for Testing and Materials, Philadelphia, ASTM STP 876, 1985 pp. 389-410.

${ }^{9}$ Russell, A. J., and Street, K. N., "Moisture and Temperature Effects on the Mixed-Mode Delamination Fracture of Unidirectional Graphite/Epoxy," Delamination and Debonding of Materials, edited by W. S. Johnson, American Society for Testing and Materials, Philadelphia, ASTM STP 876, 1985, pp. 349-370.

${ }^{10}$ Crews, J. H., Jr., Shivakumar, K. N., and Raju, I. S., "Factors Influencing Elastic Stresses in Double Cantilever Beam Specimens," NASA TM-89033, Nov.1986.

${ }^{11}$ Hashemi, S., Kinloch, A. J., and Williams J. G., "Interlaminar Fracture of Composite Materials," 6th ICCM \& 2nd ECCM Conference Proceedings, Elsevier Applied Science, London, Vol.3, July 1987, pp. 3.254-3.264.

${ }^{12}$ MSC NASTRAN User's Manual, Version 64, The MacNealSchwendler Corp., Los Angeles, Nov.1985.

${ }^{13} 0$ 'Brien, T. K., Murri, G. B., and Salpekar S. A., "Interlaminar Shear Fracture Toughness and Fatigue Thresholds for Composite Materials," NASA TM-89157, USAAVSCCOM TM 87-B-9, Aug.1987.

${ }^{14} 0$ 'Brien, T. K., "Interlaminar Fracture Toughness Testing of Composites," (to be published); supporting data available from ASTM Headquarters, request RR D30.02.02.

${ }^{15}$ Raju, I. S., "Calculation of Strain-Energy Release Rates with Higher Order and Singular Finite Elements," Engineering Fracture Mechanics, Vol.28, No.3, 1987, pp. 251-274.

${ }^{16}$ Kanninen, M. F., "An Augmented Double Cantilever Beam Model for Studying Crack Propagation and Arrest," International Journal of Fracture, Vol.9, No.1, March 1973, pp.83-92.

${ }^{17}$ Shivakumar, K. N., Personal communication, Analytical Services \& Materials, Inc., Hampton, VA, 1988.

${ }^{18}$ Aliyu, A. A., and Daniel, I. M., "Effects of Strain Rate on Delamination Fracture Toughness of Graphite/Epoxy," Delamination and Debonding of Materials, edited by W. S. Johnson, American Society for Testing and Materials, ASTM STP 876, 1985, pp.336-348.

${ }^{9}$ Carlsson, L. A., Gillespie, J. W., and Pipes, R. B., "On the Analysis and Design of the End Notched Flexure (ENF) Specimen for Mode II Testing," Journal of Composite Materials, Vol.20, Nov. 1986, pp. 594-604. 